\title{
Comparison of Growth Performance, Body Composition, Body Conforma- tion and Meat Quality Between Three Genetic Pig Lines
}

\author{
Liesbet Permentier ${ }^{1, *}$, Daniël Maenhout ${ }^{2}$, Konrad Broekman $^{5}$, Wouter Deley ${ }^{3}$, Vincent Van de \\ Perre $^{1}$, Geert Verbeke ${ }^{4}$ and Rony Geers ${ }^{1}$ \\ ${ }^{1}$ Laboratory for Quality Care in Animal Production, KU Leuven, Bijzondere weg 12, B-3360 Lovenjoel, Belgium \\ ${ }^{2}$ ForFarmers Belgium BVBA, Zuidkaai 6, B-8770 Ingelmunster, Belgium \\ ${ }^{3}$ Hypor Belgium NV, Theo De Beckerstraat 24 bus 5, B-3200 Aarschot, Belgium \\ ${ }^{4}$ Leuven Biostatistics and Statistical Bioinformatics Centre, KU Leuven, Kapucijnenvoer 35, B-3000 Leuven, Belgium \\ ${ }^{5}$ Hypor B.V., Spoorstraat 69, NL-5831 CK Boxmeer, The Netherlands
}

\begin{abstract}
Growth performance, body composition, body conformation and meat quality were evaluated in crossbred pigs originating from three sire lines selected for leanness and conformation. The crossbred $\mathrm{P}$, which was based on Belgian Piétrain had a leaner carcass and a better ham conformation compared to the other crossbreds. The presence of the halothane gene resulted in poorer meat quality in comparison to the homozygous halothane negative crossbred. Body composition and body conformation were not correlated. Hence, information on both body composition and body conformation is needed to characterize genetic lines in order to determine the true commercial value of pig carcasses, especially when meat quality has to be taken into account.
\end{abstract}

Keywords: Pig, Crossbred, Body composition, Conformation, meat quality.

\section{INTRODUCTION}

One of the major objectives of swine industry is to increase lean to fat ratio in pig carcasses. Genetic selection for decreased backfat depth combined with improved environment, realized leaner carcasses from pigs with a higher feed efficiency [1]. In European countries, the economic value of pig carcasses is based on carcass weight and lean meat content of the carcass. Usually, lean meat percentage is estimated from one-point measurements of backfat and loin muscle depth, using prediction equations developed according to EU regulation. Furthermore, each country is allowed to adapt its regulation to the European reference methods. For the last ten years, conformation, defined as the body shape of the commercial cuts of the carcass is becoming more important because of the increasing interest of the production market in the individual carcass primal cuts. Consequently, conformation has become an additional trait to determine commercial value of a carcass in some countries (e.g. The Netherlands, Belgium) [2]. Moreover, consumers and industry request carcasses with a better meat quality, as aberrant meat quality can be related to poor welfare, but also to important economic losses [3]. Hence, detailed characterization of different genetic lines for (1) lean meat content (2)

\footnotetext{
*Address correspondence to this author at the Laboratory for Quality Care in Animal Production, KU Leuven, Bijzondere weg 12, B-3360 Lovenjoel, Belgium; Tel: +32 164681 39; Fax: +32 164681 59;

E-mail: Liesbet.Permentier@biw.kuleuven.be
}

conformation scores and (3) meat quality traits are of interest for pig farmers to make appropriate decisions regarding choice of terminal sire breeds. However, overall management in terms of meeting consumer or market demands is also important $[4,5]$. Much literature is available on comparisons between non-related breeds, representative for the European meat industry and widely differing in growth performance, body composition and body conformation [5-9], pointing attention on behavioural aspects to explain differences in efficiency, while an association with hormonal profiles is not univocal $[10,11]$. However, little is known about the variation in leanness and conformation scores between different genetic lines within one breed highly selected for leanness and conformation. Therefore, three Piétrain-sired crossbreds were studied for quantifying to what extent lean meat content and conformation are related to each other. The objective of this study was to evaluate growth performance, carcass composition, body conformation and meat quality for three genetic lines highly selected for leanness and body conformation. All animals were reared, transported and slaughtered in the same conditions, in order to reduce the variability in performances of the crossbreds due to variability in environmental conditions.

\section{MATERIALS AND METHODOLOGY}

\section{Animals and Housing}

The progeny of three different Piétrain-related sire lines (P, A, B) crossed with a standard Hypor homozygous halothane negative $(\mathrm{NN})$ female were studied. Sire line $\mathrm{P}$ is 
Table 1. Overview of Experimental Design Concerning the Investigation of the Crossbreds in Relation to Time of the Year

\begin{tabular}{|c|c|c|c|c|c|c|c|c|}
\hline & Trial 1 & Trial 2 & Trial 3 & Trial 4 & Trial $5^{d}$ & Trial 6 & Trial 7 & Trial 8 \\
\hline a & Nov '07 & March '08 & June '08 & Oct ' 08 & Feb ‘09 & May '09 & Sep '09 & Jan ' 10 \\
\hline $\mathrm{b}$ & April '08 & August '08 & Dec '08 & March '09 & July '09 & Nov '09 & March ' 10 & May ' 10 \\
\hline \multirow{2}{*}{$\mathrm{c}$} & $\mathrm{P}$ & $\mathrm{P}$ & $\mathrm{P}$ & $P$ & $P$ & $P$ & $\mathrm{P}$ & $\mathrm{P}$ \\
\hline & A & B & A & B & A & B & A & B \\
\hline
\end{tabular}

${ }^{\text {a }}$ Month and year of birth

${ }^{\mathrm{b}}$ Month and year of slaughter.

${ }^{c}$ Crossbreds involved in the trial. Crossbred A = Sire line A x Hybrid sow; Crossbred B = Sire line B x Hybrid sow; Crossbred P = Belgian Piétrain boar x Hybrid sow

${ }^{\mathrm{d}}$ Pigs were omitted from analysis because of $E$. coli infection in maternal facility.

based on Belgian Piétrain which is known to have a greater lean meat percentage and body conformation, but to grow slower than other breeds [12]. Sire-line B is strongly related to German Piétrain, selected for great conformation and lean meat percentage and also a faster growth compared to sire line P. Sire line A originated from Belgian Piétrain $(75 \%)$ and York $(25 \%)$. In contrast with the other sire lines used in this study, this sire line is homozygous negative for the halothane gene $(\mathrm{NN})$ and is even more selected for growth. As all F1 sows were $\mathrm{NN}$, the progeny of sire line A was $\mathrm{NN}$, whereas the progeny of sire-line $\mathrm{P}$ and $\mathrm{B}$ were heterozygous halothane positive $(\mathrm{nN})$. Throughout the paper, each crossbred will be indicated by the term 'crossbred' followed by the code for its sire line (P, A, B).

All pigs used in this experiment were born and raised at a research facility of KU Leuven, located in a region with low density of pig farms [13], operating similarly to commercial practice. Housing conditions of all pigs were standardized according to Council Directive 2010/63/EU. In addition, all experimental procedures were approved by the ethical committee on the use of experimental animals (KU Leuven).

At birth, piglets were marked individually with an ear tag, assuring a total traceability from birth till slaughter. Male piglets were castrated one week after birth. At 4 weeks of age $(8.21 \pm 1.39 \mathrm{~kg})$, animals were weaned and moved to the nursery unit. Pigs were group housed in 6 pens according to their sire line and weight. The number of animals ranged between 12 and 15 per pen depending on the availability of pigs per trial. The available floor space ranged between 0.2 and $0.25 \mathrm{~m}^{2}$ per pig, depending on the number of animals per pen. Barrows and gilts were mixed per pen, aiming a fixed ratio of both genders per pen. The mean number $( \pm$ standard deviation) of barrows and gilts per pen was respectively 6.4 \pm 1.27 and $6.7 \pm 0.86$. After 2 weeks, the animals were moved to the growing unit with a floor space of 0.4 to $0.5 \mathrm{~m}^{2}$ per pig, depending on the number of animals per pen. To be in accordance with European legislation (EU 2008/120/EC) on available floor space at the start of the growing-finishing phase, the number of animals was reduced to 8-12 pigs per pen $(21.95 \pm 3.48 \mathrm{~kg})$, resulting in a floor space of 0.5 to $0.75 \mathrm{~m}^{2}$ per pig, depending on the number of animals per pen. Animal selection was based on the avoidance of abnormalities and extreme high or low body weights. Pigs remained with the same pen mates in order to prevent aggressive behaviour resulting from mixing. The mean number ( \pm standard deviation) of barrows and gilts per pen was respectively $5.6 \pm 0.89$ and $5.6 \pm 0.79$. Final moving, from growing to finishing unit, was at 12 weeks of age, resulting in an available floor space of 0.65 to $1.0 \mathrm{~m}^{2}$ per pig, depending on the number of animals per pen. Throughout the experiment, feeders were checked daily for proper feed flow to minimize wastage combined with proper feed intake. Moreover, drinking nipples were checked daily for adequate water supply. Ventilation and dry air temperature (i.e. between 23 and $25^{\circ} \mathrm{C}$ as measured by dataloggers (EL-USB-2 datalogger, Lascar electronics, United Kingdom)) in the housing units were computer controlled, to keep the pigs within their thermal neutral zone. During the day, the lights in the compartments, where the pigs were housed, were turned on for at least 8 hours, which is in accordance with national regulations.

\section{Experimental Design}

Data were collected during 8 trials (Table 1), spread over the 4 seasons in order to account for a seasonal effect [14, 15]. Within each trial, two crossbreds were compared, with crossbred $\mathrm{P}$ functioning as a pair wise control to the other two crossbreds, resulting in an unbalanced experiment for sample size. Within each trial, piglets were born from 2 boars per sire line and approximately 24 sows, which means a total of 16 boars per sire line and 192 sows throughout the experiment. From weaning to slaughter, all pigs had ad libitum access to water and a 5-phased standard meal diet.

\section{Data Collection}

\section{Growth Performance}

Each individual pig was weighed with an electronic scale at weaning, at the start of the growing-finishing phase and at slaughter, to calculate average daily gain. Total feed intake was measured per pen, allowing the calculation of feed efficiency per pen. At final weighing, one day before slaughter, backfat and loin muscle depth were measured on the left side of all animals between the third and fourth last rib at $5 \mathrm{~cm}$ from the midline using an electronic ultrasound device (Vetkoplus, Noveko, Lachine, Canada). Afterwards, the animals were fasted before transport to the slaughterhouse.

\section{Carcass Measures}

On the day of slaughter in the morning, all pigs were transported (134 $\pm 16 \mathrm{~min})$ to a commercial slaughterhouse over a distance of $160 \mathrm{~km}$. The pigs spent at least $1 \mathrm{~h}(92 \pm$ $29 \mathrm{~min}$ ) in lairage. Afterwards, pigs were stunned electrically using a head-to-chest method and killed by exsanguination. In the slaughter line, the pigs were split in the middle of the vertebral column and the belly in the middle of the sternum aiming two identical half carcasses. Backfat and loin muscle 
depth were measured between the third and the fourth last rib of the left side of the carcass, using a CGM device (Capteur Gras-Maigre; EU 97/107/EC, Regulation 3127/94). Lean meat content of the carcass was calculated according to the following formula (EU 97/107/EC, Regulation 3127/94):

$$
\mathrm{Y}=59.90-1.06 \mathrm{x}_{1}+0.23 \mathrm{x}_{2},
$$

where $\mathrm{Y}=$ estimated lean meat of the carcass $(\mathrm{kg})$; $\mathrm{x}_{1}=$ backfat depth $(\mathrm{mm}) ; \mathrm{x}_{2}=$ loin muscle depth $(\mathrm{mm})$. This formula is valid for carcasses weighing between $60 \mathrm{~kg}$ and $120 \mathrm{~kg}$ with $\mathrm{R}^{2}$ and RMSE respectively equal to 0.74 and 1.88. Additionally, the conformation of the ham was assessed by readings of the ham width and the ham angle that were performed by an EU certified PIC2000 device (Rovitech). Carcasses were weighed at the end of the slaughter line and dressing percentage was calculated by dividing the warm carcass weight by the final live weight which was measured before fasting.

Before transport to the slaughterhouse, 16 pigs were selected based on their final live weight $(108.5 \pm 6.8 \mathrm{~kg})$, sire line (equal number of each crossbred) and gender (equal number of barrows and gilts per crossbred). At 24 hours post-slaughter, the left half of these carcasses was jointed according to the Belgian cut [16]. Standardization of the method, in order to limit variation inherent to the methodology, was accomplished by having one experienced person who performed all dissections during all trials. The resulting four primal cuts were ham, loin, shoulder and belly. Primal cuts were weighed and the proportion of each primal cut versus total sum of primal cuts was calculated. Also, hamloin weight and proportion were calculated. Additionally, the loin was defatted. Weight of the defatted loin was measured and the proportion of the defatted loin versus total loin was calculated.

\section{Meat Quality Measurements}

At $30 \mathrm{~min}$ (i) and 24 hours (u) post-slaughter, $\mathrm{pH}$ and electrical conductivity (PQM) were measured in the loin at the last rib of the left half of the carcass. As the speed of the slaughter line did not allow measuring all carcasses, approximately half of the carcasses were measured, randomly selected. These measures were performed by the same person with the same pH-electrode (Hanna HI99163, Hanna Instruments, Temse, Belgium) and PQM meter (PQMI/KOMBI, Intek Klassifizier-ungstechnik, Aibach, Germany) throughout all trials. The $\mathrm{pH}$ electrode was cleaned with a solution specific resp. for oils (HI7077, Hanna Instruments, Temse, België) and proteins (HI7073L, Hanna Instruments, Temse, Belgium). After cleaning, the accuracy of the $\mathrm{pH}$ electrode was checked with standard solutions of $\mathrm{pH} 7$ and $\mathrm{pH} 4$, which were provided by the manufacturer. A deviation of 0.01 was tolerated, otherwise the electrode was recalibrated. Loins with a $\mathrm{pH}_{\mathrm{i}} \leq 5.9$ or a $\mathrm{PQM}_{\mathrm{i}} \geq 3.9$ were defined having more risk to develop PSE meat [14]. On the other hand, DFD meat was defined when $\mathrm{pH}_{\mathrm{u}} \geq 6.4$ [14].

Next to the $\mathrm{pH}$ and PQM measurements, the jointed pigs were sampled for additional meat quality measurements at 24 hours post-slaughter. First, the filter paper method of [17] was applied to investigate water holding capacity, by measuring drip loss. Therefore, a disc filter paper of known weight was applied for 2 seconds on a fresh cut piece. The disc filter paper absorbs juice and is weighed afterwards. Second, color was determined on the neck piece of the loin by using a Minolta Chromameter (CR-300, Minolta Inc., Osaka, Japan), based on the reflectance CIELAB coordinates $\left(\mathrm{L}^{*}, \mathrm{a}^{*}, \mathrm{~b}^{*}\right)$. Previously, the Minolta meter was calibrated with a pure white color tile.

\section{Statistical Analysis}

Data of removed (due to sickness or lameness) or dead pigs during the feeding period were omitted for growth analysis. Moreover, because of an E. coli infection in the maternal facility during trial 5 , results from this trial were omitted in the statistical analysis (Table 1). Outcomes were analysed using linear mixed models with crossbred as fixed factor and with initial body weight and gender as fixed covariate. Ultrasound measurements on the living animal and carcass measures were analysed using the same model but with final body weight as fixed covariate. For all analysed models, a possible boar, pen or trial effect was covered by adding these variables as random factors in the statistical model. Pen was considered as experimental unit when feed efficiency was analysed. For all the other variables, pig was considered as experimental unit because all these measurements were performed on animal basis. Mean estimates were calculated and differences between crossbreds were investigated by testing contrasts. Calculations were performed with the SAS procedure MIXED (version 9.2, SAS Inst. Inc., Cary, NC).

In addition, a principal component analysis was performed by using the SAS procedure FACTOR to study relationships between a selection of variables determining body conformation and body composition. In order to remove the within-cluster correlation due to trial, pen and gender effects, averages were calculated for each combination of trial, pen and gender, and these averages were used as input for the principal component analysis, after removal of systematic gender effects. The principal component analysis was performed on the resulting residuals. Throughout, a significance level of 0.05 was used.

\section{RESULTS AND DISCUSSION}

This study was designed to study growth performance, body conformation and carcass and meat quality of three Piétrain-sired crossbreds. It was stated by [18] that crossbreeding studies should be interpreted with caution because of a considerable importance of maternal effects [6]. In order to minimize this confounding effect, all pigs were born from the same maternal hybrid. Furthermore, for an optimal comparison between the three related crossbreds, an effort was made to minimize the interference from environmental effects. Therefore, all animals were reared in the same conditions of housing, environment, feeding and slaughtering.

\section{Growth Performance and Carcass Measures}

Table 2 shows an equal average initial body weight at weaning among crossbreds.

Generally, no significant differences were found between the three crossbreds. However, crossbred P tended $(0.1<\mathrm{P}<$ $0.05)$ to have a lower daily gain from 8 to $105 \mathrm{~kg}$ and a higher feed efficiency from 20 to $105 \mathrm{~kg}$ compared to the other crossbreds (Table 2 ). The higher daily gain of cross- 
Table 2. Effects of Crossbred on the Mean (Standard Deviation) Growth Performance of Pigs in the Nursery Period (8 - 20 kg), the Growing-Finishing Period (20 - $105 \mathrm{~kg})$ and Overall $(8-105 \mathrm{~kg})$

\begin{tabular}{|c|c|c|c|c|}
\hline & \multicolumn{3}{|c|}{ Crossbred $^{\mathrm{b}}$} & \multirow[b]{2}{*}{ P-value ${ }^{a}$} \\
\hline & $\mathbf{P}$ & $\mathbf{A}$ & B & \\
\hline Number of animals & 197 & 72 & 104 & \\
\hline Number of pens & 21 & 9 & 12 & \\
\hline \multicolumn{5}{|l|}{ From 8 to $105 \mathrm{~kg}$} \\
\hline Initial body weight, $\mathrm{kg}$ & $7.96(1.38)$ & $8.19(1.40)$ & $8.70(1.29)$ & 0.538 \\
\hline Final body weight, $\mathrm{kg}$ & $105.37(9.29)$ & $109.19(10.41)$ & $109.17(9.30)$ & 0.170 \\
\hline Daily gain, $\mathrm{g}$ & $636(64)$ & $674(72)$ & $658(63)$ & 0.092 \\
\hline Feed efficiency ${ }^{c}$ & $0.372(0.019)$ & $0.363(0.010)$ & $0.373(0.016)$ & 0.156 \\
\hline \multicolumn{5}{|l|}{ From 8 to $20 \mathrm{~kg}$} \\
\hline Daily gain, $\mathrm{g}$ & $364(71)$ & $392(65)$ & $375(65)$ & 0.095 \\
\hline Feed efficiency $^{c}$ & $0.529(0.032)$ & $0.523(0.049)$ & $0.535(0.024)$ & 0.155 \\
\hline \multicolumn{5}{|l|}{ From 20 to $105 \mathrm{~kg}$} \\
\hline Daily gain, $\mathrm{g}$ & $723(76)$ & $760(95)$ & 749 (78) & 0.113 \\
\hline Feed efficiency ${ }^{c}$ & $0.353(0.021)$ & $0.343(0.011)$ & $0.352(0.018)$ & 0.091 \\
\hline
\end{tabular}

${ }^{\mathrm{a}} \mathrm{P}$-values resulting from linear mixed models with crossbred as fixed effects, initial body weight and gender as fixed covariate and boar, pen and trial as random effects ${ }^{\mathrm{b}}$ Crossbred A = Sire line A x Hybrid sow; Crossbred B = Sire line B x Hybrid sow; Crossbred P = Belgian Piétrain boar x Hybrid sow

${ }^{\mathrm{c}}$ Pen was considered as experimental unit when feed and energy efficiency were analysed. Feed efficiency was calculated as total weight gain per pen divided by total feed intake per pen

bred $\mathrm{A}$ and $\mathrm{B}$ is in accordance with the higher selection for growth in sire lines A and B. Final live weight and slaughter weight were similar, resulting in a similar dressing percentage among crossbreds (Table $\mathbf{3}$ ).

In vivo ultrasound measurements as well as CGM measurements on the carcass revealed a greater loin muscle depth for crossbred $\mathrm{P}$ in comparison with the other crossbreds, whereas backfat depth was unaffected (Table 3). Moreover, a higher lean meat percentage was observed for crossbred $\mathrm{P}$ in comparison with crossbred A, reflecting the higher lean meat potential of the Nn pigs. Also, crossbred B reached a higher lean meat percentage compared to the halothane negative crossbred A. Similarly, a higher lean meat percentage measured with CGM was found for halothane positive Piétrain pigs compared to halothane negative Piétrain pigs [19,20]. Also, a higher lean meat percentage for $\mathrm{Nn}$ pigs compared to NN pigs was reported [21], based on a meta-analysis of 23 studies. Similar to the results of [22], the higher lean meat percentage was not due to an effect of backfat thickness, but solely due to an increased loin muscle depth, being associated with the role of the ryanodine receptor with respect to the hypertrophy of muscle fibres [23].

In our study, backfat and loin muscle depth were obtained at two stages around slaughter: one time in vivo at final weighing by using an ultrasound device and one time in the slaughter line by using the CGM equipment after splitting the carcasses. A moderate correlation coefficient was found for backfat and loin muscle depth between the two methods: 0.31 and 0.41 respectively. Moreover, in absolute terms a difference of $12.6 \%$ and $-10 \%$ was observed between the ultrasound measurements and the CGM measure- ments (Table 3), although both measurements were performed at the same anatomical position, i.e. between the 3rd and 4th last rib on the left half of the body or carcass. Also [19] found slightly higher correlations between lean meat percentage based on CGM on the one hand and ultrasonic backfat and loin muscle depth measurements on the other hand. Several explanations for the differences between the two methods are proposed here. Firstly, two different devices were used, one based on ultrasound reflection and one based on light reflection, but it is not possible to calibrate both on living animals, possibly leading to a severe deviation between the two measurements [20]. Secondly, the ultrasound measurements were obtained on the animal in horizontal position, whereas the CGM measurements were obtained on the carcass suspended in vertical position. [24] stated that the shape of muscle and fat areas in warm carcasses may change, resulting in a different backfat and loin muscle depth after slaughter. And finally, ultrasound measurements were performed on living animals, which can move and contract muscles, distorting the measurement [24]. Consequently, measurements of leanness should be interpreted with caution, because of the wide range of parameters that can influence the outcome: the position of the animal, the used device, anatomical position of measurement. Nevertheless, because of the low cost and great mobility of these devices [25], this may be used to predict the composition of pig carcasses before slaughter, at least if measurements can be taken with a higher degree of accuracy [19], for example by measuring when the animal is in a fixed and standardized position. A possible alternative to asses full body composition is the Dual Energy X-ray Absorptiometry technology 
Table 3. Effects of Crossbred on the Mean (Standard Deviation) in vivo Ultrasound Measurements and CGM Measurements after Slaughter

\begin{tabular}{|c|c|c|c|c|}
\hline & \multicolumn{3}{|c|}{ Crossbred $^{2}$} & \multirow[b]{2}{*}{ P-value } \\
\hline & $\mathbf{P}$ & $\mathbf{A}$ & B & \\
\hline Number of animals & 197 & 72 & 104 & \\
\hline \multicolumn{5}{|l|}{ At $105 \mathrm{~kg}$, in vivo } \\
\hline Backfat depth, ${ }^{3} \mathrm{~mm}$ & $13.58(3.05)$ & $14.17(2.19)$ & $15.29(3.31)$ & 0.222 \\
\hline Loin muscle depth, ${ }^{3} \mathrm{~mm}$ & $60.13(5.48)^{\mathrm{a}}$ & $57.18(5.52)^{b}$ & $58.36(5.65)^{\mathrm{b}}$ & 0.001 \\
\hline \multicolumn{5}{|l|}{ After slaughter } \\
\hline Slaughter weight, ${ }^{4} \mathrm{~kg}$ & $82.36(7.35)$ & $84.17(8.17)$ & $85.83(7.22)$ & 0.248 \\
\hline Dressing percentage, $\%$ & $78.19(2.15)$ & $77.13(3.06)$ & $78.68(2.90)$ & 0.260 \\
\hline Backfat depth, ${ }^{5} \mathrm{~mm}$ & $12.29(3.34)$ & $13.59(2.74)$ & $12.65(3.13)$ & 0.204 \\
\hline Loin muscle depth, ${ }^{5} \mathrm{~mm}$ & $66.84(6.16)^{\mathrm{a}}$ & $63.47(5.31)^{\mathrm{b}}$ & $65.40(5.92)^{b}$ & 0.007 \\
\hline Lean meat, ${ }^{56} \%$ & $62.18(3.67)^{\mathrm{a}}$ & $60.04(2.82)^{b}$ & $61.46(3.53)^{\mathrm{a}}$ & 0.014 \\
\hline
\end{tabular}

${ }^{\mathrm{a}, \mathrm{b}}$ Means without a common superscript letter within a row differ significantly $(\mathrm{P}<0.05)$.

${ }^{1} \mathrm{P}$-values resulting from linear mixed models with crossbred as fixed effect, final body weight and gender as covariates and boar, pen and trial as random effects.

${ }^{2}$ Crossbred A = Sire line A x Hybrid sow; Crossbred B = Sire line B x Hybrid sow; Crossbred P = Belgian Piétrain boar x Hybrid sow .

${ }^{3}$ Ultrasound measurements on the living animal.

${ }^{4}$ Slaughter weight: with head and without intestines, hair, claws.

${ }^{5} \mathrm{CGM}$ measurements after slaughter.

${ }^{6}$ Lean meat percentage is calculated according to the following formula: $\mathrm{Y}=59.90-1.06 \mathrm{x}_{1}+0.23 \mathrm{x}_{2}$, where $\mathrm{Y}=$ estimated lean meat of the carcass $(\mathrm{kg}) ; \mathrm{x}_{1}=$ backfat depth (mm); $\mathrm{x}_{2}=$ loin muscle depth $(\mathrm{mm})$.

$[26,27]$. This technique can also be used to estimate genetic differences, as demonstrated by [28, 29].

\section{Conformation Scores}

Several traits related to body conformation were scored in this study. Ham width and angle were measured on each individual carcass and in total 63 carcasses were jointed in order to measure the weight of the four primal cuts (Table 4). A significant smaller ham angle and greater ham width was found for crossbred $\mathrm{P}$ and $\mathrm{B}$ compared to crossbred $\mathrm{A}$, indicating a better conformation for these two crossbreds. No significant differences were seen for these two variables when only the selected animals for the jointing experiment were considered, which is probably caused by the smaller sample size as the averages and standard deviations of both variables was similar between the two tested groups.

Additionally, Table 4 shows that ham weight $(\mathrm{P}<0.1)$ and ham-loin weight $(\mathrm{P}<0.05)$ were greater for crossbred $\mathrm{P}$ compared to the other crossbreds, which is similar to the results of [30] and [31]. On the other hand, belly weight was significantly lower for crossbred $\mathrm{P}$ compared to the other crossbreds. Previous reports have also shown that Piétrain breeds have a smaller belly compared to other breeds $[4,5$, 32], which can be related to a shorter carcass in Piétrainsired pigs $[5,30]$.

Our results suggest that crossbred $\mathrm{P}$ and $\mathrm{B}$ had a better conformation in comparison with the halothane negative crossbred A. When the distribution of the primal cuts is considered, crossbred $\mathrm{P}$ was characterized by the highest proportion of ham and loin, and the lowest proportion of belly. This is important from an economic point of view in terms of optimizing return on the carcass, as ham and loin are the most valuable cuts of a pig carcass in Belgium. However, this is not a universal valued characteristic, as the American industry and Singapore for example attach great importance to the belly [5]. Also, for the production of Spanish dry-cured ham, the Piétrain breed is also not considered to be the most appropriate breed despite its high ham weight. Main reason for this is the lower meat quality associated with the halothane gene $[33,34]$, which is discussed in the next section.

\section{Meat Quality}

In total $\mathrm{pH}$ and PQM were measured on 213 carcasses, and color and drip loss on 63 carcasses (Table 5).

No DFD meat was detected based on the measurements of $\mathrm{pH}$ and PQM at 24 hours after slaughter, so these advantages are not shown. Also, [14] found a low prevalence of DFD meat in Belgian pigs, concluding that DFD meat does not occur very often in Belgium [35]. [36] stated that conclusions concerning meat quality are dependent on the meat quality trait considered, which was also found in this study. Some differences in meat quality traits indicating PSE meat were observed between the three crossbreds, based on $\mathrm{pHi}$ and PQMi. However, no significant differences were found for these two variables when only the selected animals were considered. This finding may be explained by the smaller sample size. Consequently, it is assumed that the larger sample size may be more representative for the population.

First, $\mathrm{pH}_{\mathrm{i}}$ was lowest for crossbred $\mathrm{P}$ and $\mathrm{B}$, whereas no differences were seen based on $\mathrm{PQM}_{\mathrm{i}}$ measurements (Table 5). The $P Q M_{i}$ value for crossbred $A$ was lowest and lower than the cut-off value of 3.9 to indicate PSE meat [14], hence, no incidence of PSE meat was found among the pigs of crossbred A. On the other hand, when a threshold of 5.9 
Table 4. Effects of Crossbred on the Mean (Standard Deviation) Weights of Primal Cuts and Proportion of Weight Versus Sum Primal Cuts after Jointing the left half of the Carcass.

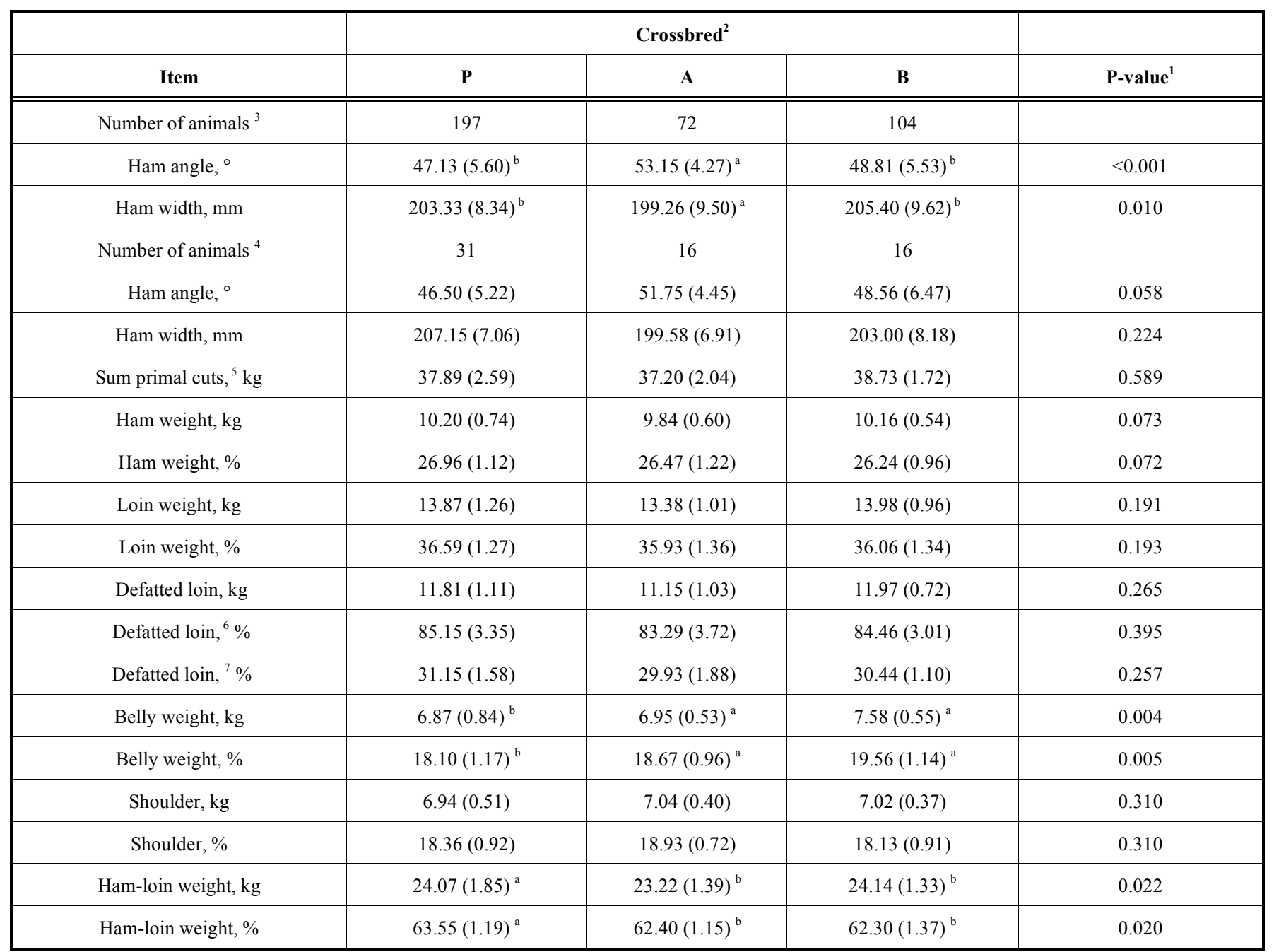

${ }^{a, b}$ Means without a common superscript letter within a row differ significantly $(\mathrm{P}<0.05)$.

${ }^{1} \mathrm{P}$-values resulting from linear mixed models with crossbred as fixed effect, sum of primal cuts and gender as fixed covariate and boar, pen and trial as random effects.

${ }^{2}$ Crossbred A = Sire line A x Hybrid sow; Crossbred B = Sire line B x Hybrid sow; Crossbred P = Belgian Piétrain boar x Hybrid sow

${ }^{3}$ Conformation scores based on measurements of all individual animals transported to the slaughterhouse.

${ }^{4}$ Conformation scores and results of jointing experiment performed on a selection of animals based on body weight, crossbred and gender (equal number of gilts and barrows per crossbred).

${ }^{5}$ Sum of primal cuts $=$ ham + loin + belly + shoulder; P-value resulting from linear mixed model with crossbred and gender as fixed effects, slaughter weight as covariate and boar, pen and trial as random effects.

${ }^{6}$ Proportion of defatted loin versus total loin.

${ }^{7}$ Proportion of defatted loin versus sum of primal cuts.

Table 5. Effects of Crossbred on Mean (Standard Deviation) meat Quality Measures

\begin{tabular}{|c|c|c|c|c|}
\hline \multirow[b]{2}{*}{ Item } & \multicolumn{3}{|c|}{ Crossbred $^{6}$} & \multirow[b]{2}{*}{ P-value ${ }^{3}$} \\
\hline & $\mathbf{P}$ & $\mathbf{A}$ & B & \\
\hline Number of animals ${ }^{1}$ & 109 & 43 & 61 & \\
\hline $\mathrm{pH}_{\mathrm{i}}$ & $6.14(0.25)^{\mathrm{a}}$ & $6.31(0.22)^{\mathrm{b}}$ & $6.03(0.19)^{\mathrm{a}}$ & 0.001 \\
\hline $\min$ & 5.60 & 5.86 & 5.46 & \\
\hline $\max$ & 6.72 & 6.83 & 6.40 & \\
\hline $\mathrm{PQM}_{\mathrm{i}}$ & $3.5(0.4)$ & $3.3(0.4)$ & $3.5(0.5)$ & 0.107 \\
\hline $\min$ & 2.7 & 2.3 & 2.7 & \\
\hline
\end{tabular}


Table 5. contd...

\begin{tabular}{|c|c|c|c|c|}
\hline \multirow[b]{2}{*}{ Item } & \multicolumn{3}{|c|}{ Crossbred $^{6}$} & \multirow[b]{2}{*}{ P-value ${ }^{3}$} \\
\hline & $\mathbf{P}$ & $\mathbf{A}$ & B & \\
\hline $\max$ & 5.0 & 3.8 & 5.3 & \\
\hline Number of animals ${ }^{2}$ & 31 & 16 & 16 & \\
\hline $\mathrm{pHi}$ & $6.11(0.22)$ & $6.20(0.26)$ & $6.02(0.26)$ & 0.321 \\
\hline PQMi & $3.5(0.6)$ & $3.2(0.5)$ & $3.6(0.6)$ & 0.470 \\
\hline Brightness $\left(L^{*}\right)^{4}$ & $53.18(7.48)$ & $53.20(4.78$ & $52.08(8.55)$ & 0.972 \\
\hline Redness $\left(a^{*}\right)^{4}$ & $11.91(2.6)^{\mathrm{a}}$ & $8.83(2.39)^{\mathrm{b}}$ & $11.13(2.49)^{\mathrm{a}}$ & 0.003 \\
\hline Yellowness (b*) ${ }^{4}$ & $5.48(2.18)$ & $4.10(1.61)$ & $5.19(2.41)$ & 0.278 \\
\hline Drip loss, ${ }^{5} \mathrm{~g}$ fluid & $0.072(0.029)$ & $0.074(0.032)$ & $0.073(0.027)$ & 0.977 \\
\hline
\end{tabular}

a,b Means without a common superscript letter within a row differ significantly $(\mathrm{P}<0.05)$.

${ }^{1}$ Meat quality measurements performed on all animals transported to the slaughterhouse. $\mathrm{pH}_{\mathrm{i}}=\mathrm{pH}$ measured at 30 minutes after slaughter; $\mathrm{PQM} \mathrm{i}_{\mathrm{i}}=\mathrm{PQM}$ measured at 30 minutes after slaughter.

${ }^{2}$ Meat quality measurements performed on a selection of animals based on body weight, crossbred and gender (equal number of gilts and barrows per crossbred). $\mathrm{pH}$ at 30 minutes after slaughter; $\mathrm{PQM}_{\mathrm{i}}=\mathrm{PQM}$ measured at 30 minutes after slaughter.

${ }^{3} \mathrm{P}$-values resulting from linear mixed models with crossbred as fixed effect, gender as fixed covariate and boar, pen and trial as random effects.

${ }^{4}$ Higher $\mathrm{L}^{*}$ value indicates a lighter color; higher $\mathrm{a}^{*}$ value indicates a redder color; higher $\mathrm{b}^{*}$ value indicates a more yellow color.

${ }^{5}$ Disc filter paper was applied for 2 seconds immediately after cutting. Drip loss = weight of filter paper after applying - weight of filter paper before applying.

${ }^{6}$ Crossbred A = Sire line A x Hybrid sow; Crossbred B = Sire line B x Hybrid sow; Crossbred P = Belgian Piétrain boar x Hybrid sow.

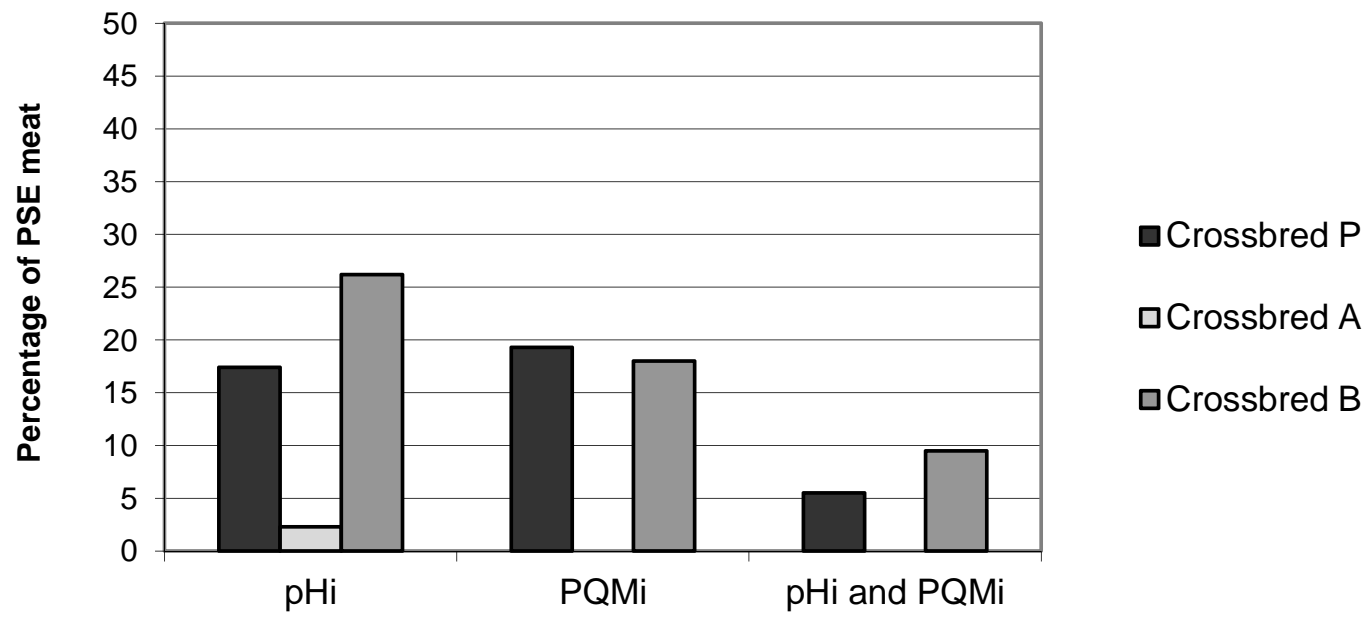

Fig. (1). Percentage of PSE meat for the three crossbreds based on $\mathrm{pH}_{\mathrm{i}} \leq 5.9, \mathrm{PQM}_{\mathrm{i}} \geq 3.9$ or on the combination of $\mathrm{pH}_{\mathrm{i}} \leq 5.9$ and $\mathrm{PQM} \mathrm{M}_{\mathrm{i}} \geq 3.9$. All transports were put together. Crossbred A = Sire line A x Hybrid sow; Crossbred B = Sire line B x Hybrid sow; Crossbred P = Belgian Piétrain boar x Hybrid sow.

[14] was used to detect PSE based on $\mathrm{pH}_{\mathrm{i}}$ measurements, 2.3 $\%$ of crossbred A was considered to be at risk to develop PSE meat, Fig. (1).

These results confirm the finding of [36] that conclusions concerning meat quality are highly dependent on the trait considered. Mostly, in industry, $\mathrm{pH}$ measurements are used to determine aberrant meat quality rather than PQM measurements. However, [14] concluded that a combination of both measurements may be a better tool to define PSE meat than one single measurement. Therefore, the percentage of PSE meat, when based on the combination of $\mathrm{pH}_{\mathrm{i}}$ and $\mathrm{PQM}_{\mathrm{i}}$ was also added in Fig. (1). Again, no risk to develop PSE meat for crossbred A and a higher risk for crossbred $\mathrm{P}$ and $\mathrm{B}$ are observed.

Second, crossbred $\mathrm{P}$ and $\mathrm{B}$ had redder meat $\left(\mathrm{a}^{*}\right)$ than crossbred A, whereas lightness $\left(\mathrm{L}^{*}\right)$ and yellowness $\left(\mathrm{b}^{*}\right)$ were similar among crossbreds (Table 5). Furthermore, the filter paper method showed no difference in drip loss.

In general, our results are in line with the common knowledge concerning meat quality in relation to the presence of the halothane gene. It is known that meat quality of genetic lines, selected against the halothane gene such as crossbred $\mathrm{A}$, is better in comparison with meat quality of $\mathrm{nn}$ 


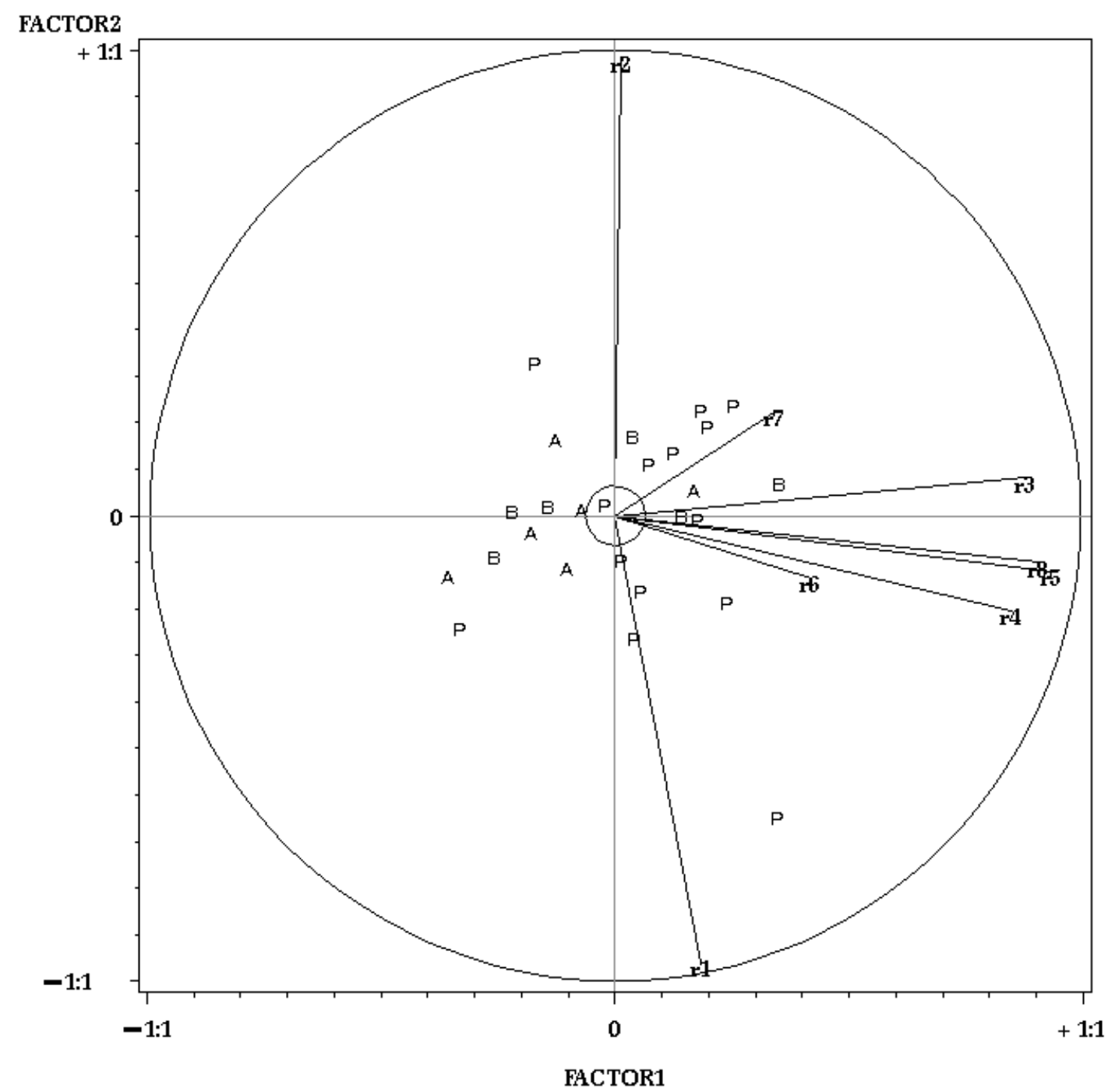

Fig. (2) Loading plot resulting from principal component analysis, demonstrating the correlation between jointing weights and body composition, clustered by crossbred. Factor 1 (57.6 \%) versus factor 2 (25.1\%). P: Crossbred P; A: Crossbred A; B: Crossbred B; r1: Backfat depth (CGM); r2: Lean meat percentage; r3: Ham weight; r4: Loin weight; r5: Defatted loin weight; r6: Belly weight; r7 Shoulder weight; r8: Hamloin weight. Crossbred A = Sire line A x Hybrid sow; Crossbred B = Sire line B x Hybrid sow; Crossbred P = Belgian Piétrain boar x Hybrid sow.

and Nn pigs [7, 36-38]. In addition, Nn pigs show a meat quality intermediate between $\mathrm{NN}$ and nn pigs [36, 37].

\section{Interrelationship between Variables and Crossbreds}

A principal component analysis was conducted to study the relationship between body conformation scores and body composition for the three crossbreds. Such an analysis is an explorative technique that aims to represent information of a wide variety of correlated variables by a restricted number of factors. Only 6 variables regarding body conformation and 2 variables regarding body composition were applied, because of the rather low correlations between the other variables. [39] reported significant correlations $(r=-0.45)$ between average daily gain and intramuscular fat content, suggesting that pigs with a high feed intake, grow faster and deposit mainly fat, whereas pigs with a high growth rate have a higher feed intake capacity and deposit mostly protein. Body conformation was represented by the primal cut weights and body composition by backfat depth measured with CGM and lean meat percentage. Three factors were obtained which accounted for $89.9 \%$ of the total variability found between animals. Two loading plots are represented, using the first two factors on the one hand, Fig. (2), and the first versus third factor on the other hand, Fig. (3).

In such a loading plot, lines are used to reflect the variables, whereas the observations of the three crossbreds are represented by $\mathrm{P}, \mathrm{A}$ or $\mathrm{B}$. The length of the line represents the variability that is accounted for, by that variable. Generally, it may be assumed that the longer the line, the higher is the variability. All variables, shown in Fig. (2), have long lines, suggesting that these variables may be well represented by the first two factors, except for shoulder and belly weight. The first factor explained $57.6 \%$ of the variability and was positively defined by body conformation, whereas the second factor explained $25.1 \%$ of the variability and was positively defined by lean meat percentage. The shorter line of shoulder and belly weight suggests that these variables are not well determined by the first two factors. The third factor explained $7.2 \%$ of the variability among animals and was also determined by conformation. In a loading plot, variables 


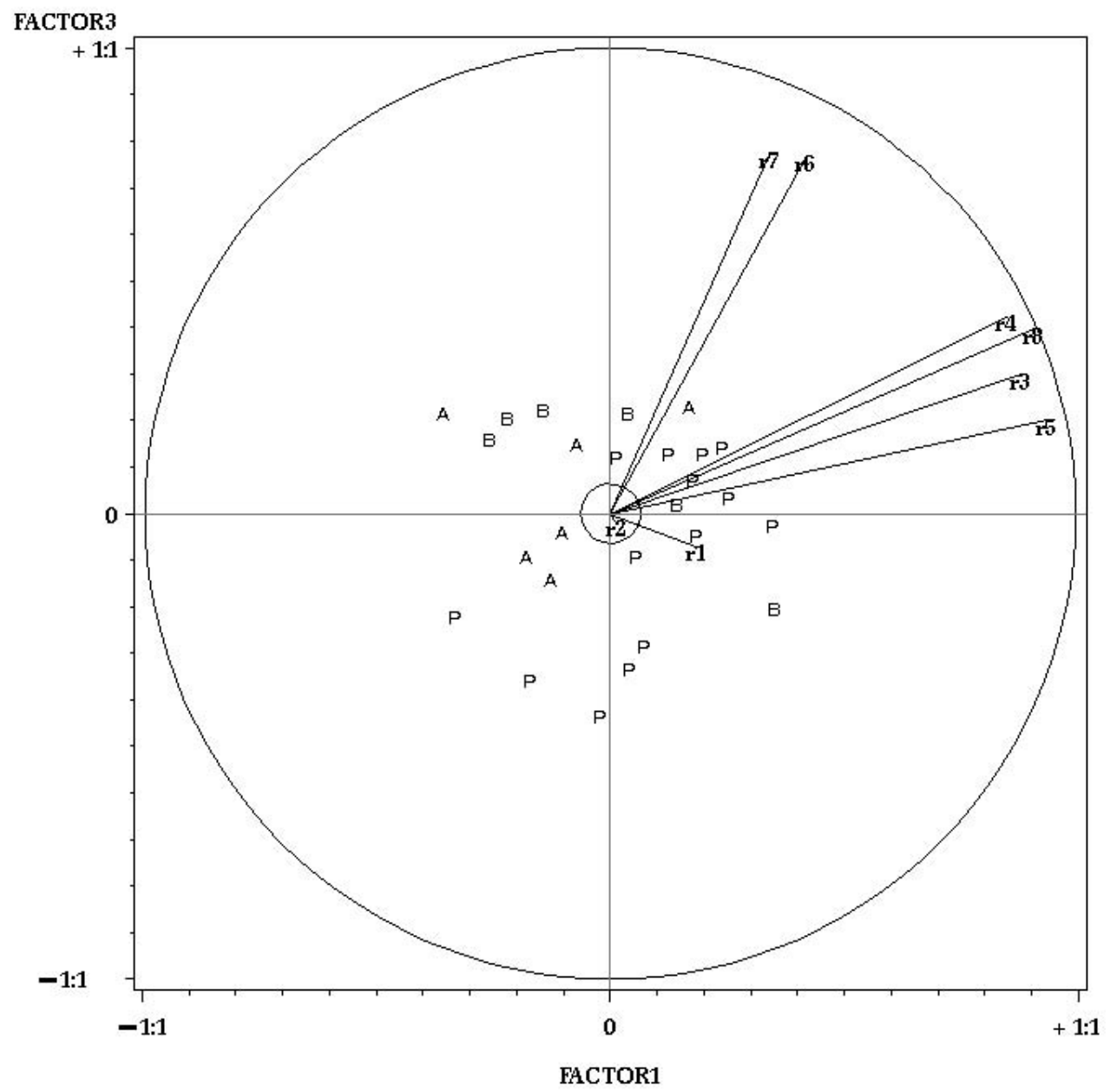

Fig. (3). Plot resulting from principal component analysis, demonstrating the correlation between body conformation scores and body composition, clustered by crossbred. Factor 1 (57.6 \%) versus factor 3 (7.2 \%). P: Crossbred P; A: Crossbred A; B: Crossbred B; r1: Backfat depth (CGM); r2: Lean meat percentage; r3: Ham weight; r4: Loin weight; r5: Defatted loin weight; r6: Belly weight; r7 Shoulder weight; r8: Ham-loin weight. Crossbred A = Sire line A x Hybrid sow; Crossbred B = Sire line B x Hybrid sow; Crossbred P = Belgian Piétrain boar x Hybrid sow.

close to each other are positively correlated, whereas variables found in orthogonal direction are independent of each other. Overall, no correlation was seen between body conformation and body composition traits, Fig. (2). Comparison of the three crossbreds for the first two factors revealed that crossbred $\mathrm{P}$ is rather positively defined by conformation, reflecting the higher selection for conformation in sire line $\mathrm{P}$. On the contrary, crossbred A is less related to the conformation scores and crossbred B is widespread around the center, suggesting that this crossbred is intermediate between crossbred $\mathrm{P}$ and A. In Fig. (3), two groups of correlated variables can be distinguished: one group with shoulder and belly weight and one group with the higher valued cuts, ham and loin. Comparing the three crossbreds in the plot for the first versus third factor, Fig. (3), revealed that crossbreds A and B had a lower ham and loin weight than average (centre of figure). Several observations of crossbred $\mathrm{P}$ are positively related to ham and loin weight, whereas some observations have lower ham and loin weight, suggesting a high variability among the animals of this crossbred for ham and loin weight. The loading plot of [5] who compared body composition and conformation among five different genetic breeds, indicated that the Piétrain breed was well distinguished from other non-related breeds. When comparing highly related genetic lines within one breed, such as in our study, the loading plot confirms the close relationship between the three Piétrain crossbreds. Nevertheless, some differences regarding body conformation between our crossbreds emphasizes the need to determine the commercial value of a pig carcass on carcass leanness as well as on the body shape of the carcass. Moreover, our results indicate that criteria can be selected for and within the appropriate crossbred to meet consumer or market demands as was already found for nonrelated breeds $[5,30]$.

\section{CONCLUSION}

A proper characterization of genetic lines requires measurements of carcass leanness, body conformation and meat quality to predict the commercial value of pig carcasses. Measures of ham and loin weight might improve prediction compared to the currently used ham angle and ham width. Body composition in this study was measured at slaughter, revealing small differences between the three crossbreds. However, these measurements were based on one 
However, these measurements were based on one single point measurements. A deeper investigation of differences in body composition between different genetic lines within one breed may require more sophisticated equipment and consequently further research. Differences in meat and carcass quality between different halothane types were confirmed in this study: the presence of the halothane gene was strongly related to a higher lean meat percentage, better ham conformation scores and a higher PSE risk.

\section{CONFLICT OF INTERESTS}

The authors confirm that this article content has no conflicts of interest.

\section{ACKNOWLEDGEMENTS}

The project was funded by IWT-Vlaanderen (Institute for the Promotion of Innovation through Science and Technology in Flanders) and KU Leuven. We are grateful to the staff of the Zootechnical Centre for taking care of the animals and the assistance for the duration of this project and to the staff of the Covameat slaughterhouse in Wijtschate for the efforts and accommodation to perform the carcass dissections.

\section{REFERENCES}

[1] Campbell RG, Taverner MR. Genotype and sex effects on the relationship between energy intake and protein deposition in growing pigs. J Anim Sci 1988; 35(66): 676-86.

[2] Doeschl-Wilson AB, Green DM, Fisher AV, Carroll SM, Schofield CP, Whittemore CT. The relationship between body dimensions of living pigs and their carcass composition. Meat Sci 2005; 70: 22940.

[3] Kuo CC, Chu CY. Quality characteristics of Chinese sausages made from PSE pork. Meat Sci 2003; 64: 441-9.

[4] Edwards DB, Bates RO, Osburn WN. Evaluation of Duroc- vs. Piétrain-sired pigs for carcass and meat quality measures. J Anim Sci 2003; 81: 1895-99.

[5] Gispert M, Font i Furnols M, Gil M, et al. Relationship between carcass quality parameters and genetic types. Meat Sci 2007; 77: 397-404.

[6] Blasco A, Gou P, Gispert M, et al. Comparison of five pig crosses. I. Growth and carcass traits. Livest Prod Sci 1994; 40: 171-8.

[7] García-Macías JA, Gispert M, Oliver MA, et al. The effects of cross, slaughter weight and halothane genotype on leanness ad meat and fat quality in pig carcasses. Anim Sci 1996; 63: 487-96.

[8] Gil M, Delday MI, Gispert M, et al. Relationship between biochemical characteristics and meat quality of Longissimus thoracis and Semimembranosus muscles in five porcine lines. Meat Sci 2008; 80: 927-33.

[9] Alonso V, Campo MdM, Español S, Roncalés P, Beltran JA. Effect of crossbreeding and gender on meat quality and fatty acid composition in pork. Meat Sci 2009; 81: 209-17.

[10] Litten JC, Corson AM, Hall AD, Clarke L. The relationship between growth performance, feed intake, endocrine profile and carcass quality of different maternal and paternal lines of pigs. Livest Prod Sci 2004; 89: 33-9.

[11] Lepron E, Bergeron R, Robert S, Faucitano L, Bernier JF, Pomar C. Relationship between residual energy intake and the behavior of growing pigs from three genetic lines. Livest Sci 2007; 111:104-13.

[12] Lean IJ, Curran MK, Duckworth JE, Holmes W. Studies on Belgian Piétrain pigs 1. A comparison of Piétrain, Landrace, and Piétrain Landrace crosses in growth, carcass characteristics and meat quality. Anim Prod 1972; 15: 1-9.

[13] Huirne RB, Windhorst HW. Development of prevention and control strategies to address animal health and related problems in densely populated livestock areas of the community. Brussels (Belgium): European Commission; 2003. p. 234 Report No.: EUR 20576 .
[14] Van de Perre V, Ceustermans A, Leyten J, Geers R. The prevalence of PSE characteristics in pork and cooked ham - Effects of season and lairage time. Meat Sci 2010a; 86: 391-7.

[15] Van de Perre V, Permentier L, De Bie S, Verbeke G, Geers R. Effect of unloading, lairage, pig handling, stunning and season on $\mathrm{pH}$ of pork. Meat Sci 2010b; 86: 931-937.

[16] Belgian meat office. Belgian meat cutting [internet]. Vlaams centrum voor Agro- en Visserijmarketing; 2013 [cited 2012 Sep 13]. Available from: http://www.belgianmeat.com/.

[17] Kauffman RG, Wachholz D, Henderson D, Lochner JV. Shrinkage of PSE, normal and DFD ham during transit and processing. $J$ Anim Sci 1978; 46: 1236-40.

[18] McLaren DG, Buchanan DS, Johnson RK. Individual heterosis and breed effects for postweaning performance and carcass traits in our breeds of swine. J Anim Sci 1987; 64: 83-98.

[19] Youssao IAK, Verleyen V, Leroy PL. Prediction of carcass lean content by real-time ultrasound in Piétrain and negative stress Piétrain. Anim Sci 2002a; 75: 25-32.

[20] Youssao IAK, Verleyen V, Michaux C, Leroy PL. A comparison of the Fat Lean Meter (CGM), the ultrasonic device Pie Medical 200 and the Piglog 105 for estimation of the lean meat proportion in Piétrain carcasses. Livest Prod Sci 2002b; 78: 107-14

[21] Salmi B, Trefan L, Bloom-Hanse J, Bidanel JP, Doeschl-Wilson $\mathrm{AB}$, Larzul C. Meta-analysis of the effect of the halothane gene on 6 variables of pig meat quality and on carcass leanness. J Anim Sci 2010; 88: 2841-55

[22] Van den Maagdenberg K, Stinckens A, Claeys E, Buys N, De Smet $\mathrm{S}$. Effect of the insulin-like growth factor-II and RYR1 genotype in pigs on carcass and meat quality traits. Meat Sci 2008; 80: 293303.

[23] Pedersen PH, Oksbjerg N, Karlsson AH, Busk H, Bendixen E, Henckel P. A within litter comparison of muscle fibre characteristics and growth of halothane carrier and halothane free crossbreed pigs. Livest Prod Sci 2001; 73: 15-24.

[24] Mersmann HJ. Ultrasonic determination of backfat depth and loin area in swine. J Anim Sci 1982; 54: 268-75.

[25] Szabo Cs, Babinszky L, Verstegen MWA, Vangen O, Jansman AJM, Kanis E. The application of digital imaging techniques in the in vivo estimation of the body composition of pigs: review. Livest Prod Sci 1999; 60: 1-11.

[26] Mitchell AD, Conway JM, Pots WJE. Body composition analysis of pigs by Dual-Energy X-ray Absorptiometry. J Anim Sci 1996; 74: 2663-71.

[27] Geers R, De Pauw B, Spincemaille G, Villé H, Vits J, Rombouts G, Duchateau W, Perremans S. The integration of DEXA, ultrasound scans and growth modeling technology to estimate body composition in growing pigs. In: McCracken K, Unsworth EF, Wylie ARG, editors. Proceedings of the $14^{\text {th }}$ Symposium on energy metabolism; 1997 Sep 14-20; Newcastle, Northern Ireland. Wallingford, Oxon: UK; 1998. p. 201-4.

[28] Marcoux M, Faucitano L, Pomar C. Carcass ans primal cut composition of different pig genetic lines by dual-energy X-ray absorptiometry (DEXA). Canadian meat science association News 2004 July: 6-8.

[29] Marcoux M, Faucitano L,Pomar C. The accuracy of predicting carcass composition of three different pig genetic lines by dual energy X-ray absorptiometry. Meat Sci 2005; 70: 655-63.

[30] Fisher AV, Green DM, Whittemore CT, Wood JD, Schofield CP. Growth of carcass components and its relation with conformation in pigs of three types. Meat Sci 2003; 65: 639-50.

[31] Gispert M, Font i Furnols M, Gil M, Velarde A, Diestre A, Carrión D, Sosnicki AA, Plastow GS. Relationship between carcass quality parameters and genetic types. Meat Sci 2007; 77: 397-404.

[32] Fàbrega E, Manteca X, Fon J, et al. Effects of halothane gene and pre-slaughter treatment on meat quality and welfare from two pig crosses. Meat Sci 2002; 62: 463-72.

[33] Oliver MA, Gou P, Gispert M, et al. Comparison of five types of pig crosses. II. Fresh meat quality and sensory characteristics of dry cured ham. Livest Prod Sci 1994; 40: 179-85.

[34] Candek-Potokar M, Monin G, Zlender B. Pork quality, processing and sensory characteristics of dry cured hams as influenced by Duroc crossing and sex. J Anim Sci 2002; 80: 988-96.

[35] Guárdia MD, Estany J, Balasch S, Oliver MA, Gispert M, Diestre A. Risk assessment of DFD meat due to pre-slaughter conditions in pigs. Meat Sci 2005; 70: 709-16. 
[36] De Smet SM, Pauwels H, De Bie S, Demeyer DI, Callewier J, Eeckhout W. Effect of halothane genotype, breed, feed withdrawal, and lairage on pork quality of Belgian slaughter pigs. J Anim Sci 1996; 74: 1854-63.

[37] Casteels M, Van Oeckel MJ, Boschaerts L, Spincemaillé G, Boucqué $\mathrm{ChV}$. The relationship between carcass, meat and eating quality of three pig genotypes. Meat Sci 1995; 40: 253-69.
[38] Van Oeckel MJ, Warnants N, Boucqué ChV, Delputte P, Depuydt $\mathrm{J}$. The preference of the consumer for pork from homozygous or heterozygous halothane negative animals. Meat Sci 2001; 58: 24751.

[39] Latorre MA, Pomar C, Faucitano L, Gariépy C, Méthot S. The relationship within and between production performance and meat quality characterstics in pigs from three different genetic lines. Livest Sci 2008; 115: 258-67.

Received: June 24, 2013

(C) Permentier et al.; Licensee Bentham Open.

This is an open access article licensed under the terms of the Creative Commons Attribution Non-Commercial License (http://creativecommons.org/licenses/by-nc/3.0/) which permits unrestricted, non-commercial use, distribution and reproduction in any medium, provided the work is properly cited. 